\title{
MÁS TEATRO FRANCÉS EN JUDEOESPAÑOL
}

\author{
ELENA ROMERO
}

CSIC. Madrid

En la monografía sobre el teatro sefardí que publiqué hace ya algunos años recogía una lista bibliográfica de las ochenta y dos obras de teatro judeoespañol que por aquel entonces conocía o de cuya publicación tenía alguna noticia '.

Hora es ya de hacer algunas nuevas precisiones y de ampliar en parte la lista entonces fijada, con sendas versiones judeoespañolas de dos obras de Molière, El avaro y El matrimonio forzado, y una de la Esther de Racine. La primera y la última quedaban recogidas con asterisco en mi citada bibliografia ${ }^{2}$, ya que por entonces no habían llegado a mis manos, en tanto que de la última tuve conocimiento una vez cerrado el corpus.

Pero antes de entrar en la descripción de las ediciones me parece conveniente examinar las introducciones de El avaro y de Ester, ambas publicadas en El Tiempo de Constantinopla en 1881 y 1882 , respectivamente. He aquí las palabras del Prefación de la primera (págs. 3-4) :

El [Molière] compośó sobre las mañas demudadas de las personas unas comedias muy interesantes, que en haciendo divertir al pueblo, lo haće también tornar de su camino yerado. Ansí las comedias que repreśentan en los teatros no son hechas sólo por reir, ma también por un deprendimiento, según lo verán con la comedia que venimos de publicar, llamada El escaso.

${ }^{1}$ E. ROMERo, El teatro de los sefardies orientales, Madrid 1979 [abrev. Teatro], vol. II, págs. 825-875. En dicha lista quedaban integradas las obras por mí descritas en otros dos artículos bibliográficos: "Teatro judeoespañol aljamiado: Adiciones bibliográficas", Sefarad XXVIII (1968) 403-408, y en la parte cuarta de "El teatro entre los sefardíes orientales», Sefarad XXIX-XXX (1969-1970), XXX (1970) 483-508.

${ }^{2}$ Teatro, nos 3 y 4 (pág. 830); puede verse allí las fuentes de donde tomaba los datos. 
Esta es una comedia que haće muncho divertir (pasar la hora), y se puede muy bien jugar entre los amigos y famillas como también en público ... Nośotros haćemos una preba en treśladando la comedia El escaso, con la esperanza que encorajándomos los señores y amatores de teatros nos ocuparemos a treśladar otras comedias que fueron hechas por los que haćen parada de ['fingen tener'] grande saber y no saben nada, por los que se imaǵinan de estar haćinos ['enfermos'] y que a fuerza de esta imaǵinación se haćen de verdad haćinos, y semejante, que todas ellas mostran la manera de los caracteres (midot) de la gente y percuran por adobarlos...

Recomandamos a los meldadores ['lectores'] que melden este libro con atención y a vagar: no como una gaćeta, ma como una conversación, en teniendo tino de la demanda y repuesta, como también entender bien los personajes (los jugadores de la comedia) y no dar de pasada sin saber tal pedazo quen debe jugarlo. Es de esta manera que trae más plaćer en meldando o en viendo jugar una comedia.

Conviene recordar que esta edición de $E l$ avaro corresponde a épocas tempranas del nacimiento del desarrollo del teatro sefardí, ya que es la de 1873 la fecha más antigua que hemos podido precisar en cuanto a ediciones y representaciones de obras de teatro ${ }^{3}$. Por ello no extraña encontrar aquí la idea que perdurará a lo largo de los tiempos hasta bien entrado el siglo XX: la de que el teatro es un maestro reprensor de malos hábitos capaz de encauzar al público asistente o lector hacia las buenas costumbres. Tal es el argumento que se hace preciso esgrimir para convencer, a veces sin éxito, a los elementos más retrógrados de la comunidad, quienes se opusieron con fortaleza a los nuevos vientos literarios que empezaron a soplar por las comunidades sefardíes de los Balcanes desde el último tercio del siglo XIX.

La obra se recomienda para ser representada, y de la ley de la oferta y la demanda, es decir, de las "demandas" de los incipientes grupos de actores aficionados que necesitan de un más amplio repertorio teatral dispuesto en versión judeoespañola para llevar a cabo su actividad, depende el que los anónimos traductores del periódico El Tiempo sigan en la brecha. Las otras comedias que se ofrecen son evidentemente algunas de las muchas en que Molière

${ }^{3}$ Tal es la fecha de la edición más antigua que conozco, la de El médico juguetón, también publicada en El Tiempo de Constantinopla, y la de la primera representación datada con seguridad, la de La salidura de los judiós de Misrdyim en la misma ciudad. Vid. al respecto Teatro: “Bibliografia», vol. II, n 1 y "Cartelera», vol. II, nos 8-9. 
pone en solfa a los que fingen conocimientos que no tienen, y a $E l$ enfermo imaginario. No nos han llegado, sin embargo, datos de que en El Tiempo vieran la luz otras obras de Molière después de ésta, y de hecho la única versión que conozco de El enfermo imaginario no se publicó hasta doce años después, en Sofia $1903{ }^{4}$.

No deja de resultar singular las recomendaciones últimas sobre la forma de leer y de ver una obra teatral que desde luego apuntan a una de las siguientes dos cosas o quizás a ambas: a la inexperiencia teatral del "respetable», o a la injustificada desconfianza de los jóvenes noeintelectuales, que con afán paternalista buscan culturizar a un público aún sorprendido por las nuevas modas literarias tan ajenas a cuanto hasta aquel momento se había producido e impreso en el mundo sefardí, anclado en su inmensa mayoría en la tradición secular del judaísmo.

En el prefacio de Ester entre otras cosas se dice (pág. 3):

Procurándomos el manuscrito de un mancebo nuestro coreliǵionario que treśladó en una habla entendible dita traǵedia del puro francés, nos apresuramos por estamparla. Estamos seguros que los judiós de Turquía recibirán con plaćer esta traǵedia y percurarán a darla en repreśentación teatral, siendo se tiene muncho más guste en verla que en meldarla, y de esta manera nos encorajamos a treśladar y a estampar otras tragedias y comedias.

En este caso no es necesario insistir en la moralidad desde el punto de vista judío, ya que el mismo tema lo asegura al tratarse de una historia que pertenece al acervo tradicional, sin que haya en él nada de foráneo o que lleve en sí las simientes del pensaniento ajeno que constituye el mundo cultural cristiano de occidente. Lo más importante de este texto es la insistencia en lo que es la esencia del teatro: algo para visto y no para leído.

Hagamos ahora un repaso de los textos desde el punto de vista literario y de su andadura en el mundo sefardís.

"Vid. Teatro: «Bibliografía», no 27 y «Repertorio dramático", n² 228.

${ }^{5}$ De las primeras y última manejo ejemplares de la Biblioteca de la Alianza Israelita Universal de París, a cuya bibliotecaria Y. Levyne agradezco la amabilidad de permitirme obtener fotocopia. En cuanto a la segunda, uso reproducción del ejemplar de mi querido amigo David Bunis, a quien agradezco asimismo el habérmela remitido. Para la comparación me he servido de los originales franceses de Esther, Le Mariage forcé y L'Avare publicados respectivamente en Classiques Illustrés Vaubourdolle, París: Hachette, 1935, Molière, Oeuvres complètes, París: Éditions du Seuil, 1962 págs. 224-237, y Classiques Larousse, París 1933. 
Ester, traǵedia en 3 actos del célebre escritor francés Racín, tirada de la Escritura santa, treśladada del francés por un anónimo... -Cospoli, 1882 - 5642.- Estampada por la prima veź en la estamparía del jornal El Tiempo...- 56 ps.; $19 \times 12 \mathrm{~cm}$.

Se trata de una puntual adaptación en prosa del original francés en verso, del que difiere en muy poco: desaparece aquí el prólogo a cargo de la Piedad que abre la obra de Racine; en el acto segundo se ha computado como escena 8 la entrada de Hidaspe para anunciar al rey la llegada de los sabios caldeos, con lo que pasa a tener 9 escenas en lugar de las 8 del original; y en la escena 9 del tercer acto se omite el parlamento de "L'Autre: Les charmes de son coeur sont encore plus puissants. / Jamais tant de vertu fut-elle couronée?», omisión que debemos entender como un simple despiste del traductor.

No parece necesario dar aquí la lista de los personajes, que salvo los esperados cambios gráficos y reestructuración en hebreo de los nombres bíblicos no ofrecen ninguna singularidad.

La obra que nos ocupa fue varias veces representada ante los públicos sefardíes; sabemos que lo fue en Serre 1909 en adaptación de Mercado Y. Cobo, quien escribió al menos los textos de dos de los cinco pasajes de la obra destinados al coro. Posiblemente fuera esta misma versión la representada en Salónica $1935^{\circ}$. Un diálogo de la tragedia se representó en Salónica 1930 y la obra entera allí mismo en 1934 '. No podemos determinar si la versión utilizada fue la que estudiamos o alguna otra; lo que sí podemos ahora afirmar es que no tienen paralelos en ésta las muestras textuales que nos han llegado de los dos cantos del coro en la citada adaptación de Cobo.

${ }^{6}$ Véase al respecto las noticias que publico en mi libro Repertorio de noticias sobre el mundo teatral de los sefardies orientales, Madrid 1983, [abrev. Repertorio], nos 308, 318, 322, 423, 632 y 885, y Teatro: "Tema de Ester", vol I, págs. 599-607.

7 Véase Teatro: “Tema de Ester», vol. 1, págs. 599-607, y Repertorio, nos, 792 y 882-883. 
El caśamiento forzado de Molier, comedia en 1 acto treśladada del francés por Selomó b. Astrug.- Viena, 1890 - 5650. - 46 ps. $19 \times 12 \mathrm{~cm}$.

Es ésta la única versión sefardí que nos ha llegado impresa de la popular comedia de Molière, pero para esas fechas la obra era ya conocida en judeoespañol, pues en esta lengua había sido representada en Rodas $1886^{\circ}$. Posteriormente en 1910, lo sería también en Adrianópolis y en Salónica ?.

En la obrita intervienen los siguientes personajes (pág. 3): Sganarel, «amorośo de Dorimén»; Jerónimo; Pancrás, «filósofo»; Marfurius, "filósofo"; Alcantor, "padre de Dorimén y de Alcidas"; Dorimén, "hija de Alcantor, amante de Licast»; Alcidas, "hijo de Alcantor"; y Licast, "amante de Dorimén". Han desaparecido las dos egipcias, es decir, las dos gitanas del original, y de forma bastante diferente se caracteriza en éste a Pancrace, "docteur aristotélicien»; Marphurius, "docteur pyrrohonien»; y Dorimène, «jeune coquette promise à Sganarelle».

El texto judeoespañol sigue de cerca el original francés, respecto al que sólo observamos algunas diferencias. Unas son de tipo formal, y así la obrita aparece segmentada en 15 escenas en la versión judeoespañola frente a las 10 del original. El aumento se debe a que en el texto sefardí se computan como tales los monólogos de Sganarelle al inicio de la obra y al final de las escenas 1,4 y 6-8 del original. Frente a ello desaparece en nuestra versión la escena 6, en donde Sganarelle consulta a las gitanas sobre su futuro.

En cuanto a los cambios de contenido, además del ya señalado de la omisión de una escena, que en nada modifica el argumento de la obra, observamos algunas reducciones y amplificaciones no demasiado significativas, en las que no vamos a entrar, así como algunos cambios, de los que señalaremos los que parecen más interesantes.

Varios responden al deseo de acercar la acción al mundo sefardí

8 Vid. Repertorio ne 36.

9 Vid. Repertorio nol 363 y 372-374, 377-378, respectivamente. 
de la Constantinopla de 1890. Así cuando en el original (esc. 1) Géronimo le dice a Sganarelle un impreciso "De cinquante-six à soixante-huit il y a douze ans», en la versión judeoespañola leemos (esc. 2) "Del 1878 al 1890 hay 12 años", trasladando con ello el traductor la acción a su presente temporal. En la conversación que el protagonista mantiene con Pancrace (esc. 4), éste indaga en sucesivas preguntas en qué lengua van a hablar, ofreciendo las siguientes posibilidades: italiano, español, alemán, inglés, latín, griego, hebreo, siríaco, turco o árabe; en todos los casos niega Sganarelle, zanjando la cuestión con un enérgico «Non, non; français». En la versión judeoespañola (esc. 6), de las lenguas ofrecidas ha desaparecido el español, sumándose el francés, para replicar finalmente Sganarelle de forma aún más contundente: «No, no, no, no, no; judeśmo, judeśmo, judeśmo».

Otros cambios responden sin duda a la autocensura a la que el traductor se somete para atenuar algunos de los pasajes de la obra de Molière que sin duda le parecen en exceso picantes.

Así, por ejemplo, al encontrarse el enamorado Sganarelle con su querida Doriméne, le dice aludiendo a su próxima boda (esc. 2): "Yo podré hacer con vos todo cuanto me plazca sin que nadie se escandalice", frase que ha desaparecido de la versión judeoespañola (esc. 4), como también del mismo parlamento se omite la mención de "les petits tétons rondelets" y del significativo en sus puntos suspensivos "de votre..." que le sigue, en tanto que les "lèvres appétissants» se han convertido en unos menos incitadores «labios colorados».

En la traducción (esc. 8) se omite la frase de Sganarelle en la que le expresa a Marphurius sus serios temores "d'être cocu" (esc. 5); y el mismo temor que resurge veladamente más adelante (esc. 7), al decidir Sganarelle que si el asunto le ha costado hasta ese momento algún dinero, «il vaut mieux encore perdre cela que de m'exposer à quelque chose de pis", se trueca en nuestra versión (esc. 11) en "ya vale mejor pedrer esto que de meter más al lado", frase que parece seguir aludiendo a asuntos de dinero.

Quizá tenía motivos el traductor para efectuar tales cambios, pues lo cierto es que en 1874, algunos años antes de la edición que comentamos, las autoridades comunitarias de Esmirna habían prohibido la representación que de esta obra había organizado un grupo 
de actores aficionados de esa ciudad y el escándalo de la suspensión saltó a las páginas de la prensa de Constantinopla ${ }^{10}$.

Señalemos, por último, la confusión permanente del manipulador sefardí en las numerosas frases expresadas en latín más o menos macarrónico, en donde insiste en traducir el et latino, probablemente entendiendo que se trata de la conjunción francesa.

El escaso, comedia de Molier, estampada por la prima veź en la estamparía del jornal El Tiempo...- Costán, 27 tišrí 5642 [= 1881] " ... -72 ps.; $15 \times 11,5 \mathrm{~cm}$.

Nos encontramos en este caso no con una mera traducción sino con una remodelación profunda, y en ocasiones muy hábil, del original francés.

Estos son los personajes de nuestra versión: Arpagón, «escaso, padre de Anrico»; Anrico, "hijo de Arpagón, el cual dio palabra a Iśabela de tomarla por novia»; Iśabela, «una donćella muy honesta y hermośa, ma probe, que se acordó con Anrico por tomarla por novia»; Ham Šm ‘ón, "coredor»; Alberto, "mozo de Anrico»; "Una chibilachos [?]», denominada más tarde Rośina (p. 36 y ss.); "Un guiśandón ['cocinero']», llamado Antonio (p. 48); "Un arab̧aği ['cochero']»; "Dos mozos»; "Una serviciala», llamada bula ['señora'] Miriam (p. 45); y Se. Ferdinando, "padre de Iśab̧ela».

Ante tal lista vemos que han desaparecido los personajes de Élise, hija de Harpagon, y de su enamorado Valère, así como el comisario y su ayudante. El hijo de Harpagon, Cléante, se llama ahora Anrico y también cambian de nombre la Mariane del original, que hay que identificar con Iśabela; Anselme, que es el Se. Ferdinando; Frosine "femme d'intrigue", que ahora pasa a ser Rosina; "dame» Claude, que es bula Miriam; y La Flèche, que es Alberto.

10 Vid. al respecto nuestro comentario en Teatro: "Repertorio dramático», vol. I, $\mathrm{n}^{2}$ 53, y los textos publicados en Repertorio nos 17-18 y 27. Sobre otras representaciones de esta obra vid. Repertorio, nos 36, 363, 372-374 y 377-378.

"Debo, pues, rectificar la fecha de 1882 que anotaba en Teatro a partir de los datos de M. Franco, Essai sur l'Histoire des Israélites de l'Empire Ottoman depuis les origines jusqu'd nos jours, Parls 1897, pág. 274, quien no advirtió que el mes de tiśŕ del 5642 corresponde a 1881 . 
En el original los "dos mozos" de Harpagon se denominan Brindavoine y La Merluche, mientras que Maître Jacques, que es a la vez cocinero y cochero de Harpagon, se desdobla ahora en dos personajes, correspondiéndole al primero el nombre de Antonio.

De todos estos cambios de nombres, los únicos que responden a un acercamiento al mundo sefardí son los de bula Miriam y ham Šim'ón, en donde además de aparecer el nombre escrito a la hebrea se usa el apelativo ham, abreviación familiar de hajam, para traducir el "maître» del original. Los demás nombres, que no son en ningún caso específicamente sefardies, responden sin embargo a un nivel neutro más cercano al público al que estaba dedicada esta versión que los nombres, muchos de ellos con resonancias clásicas, de la obra de Molière.

Numerosos son los cambios a los que el traductor ha sometido la obra que traduce, los cuales consisten mayoritariamente en reducciones y supresiones de parlamentos y en ocasiones en desgloses de los mismos, así como en no pocas ampliaciones e invenciones. El resultado se plasma en primer lugar en una diferente organización textual, ya que la versión sefardí presenta sólo cuatro actos y no los cinco del original, con 8 escenas en el primero, 6 en el segundo, 12 en el tercero y 7 en el cuarto, frente a las 5 escenas en los actos primero y segundo, 9 en el tercero y 6 en el cuarto y quinto del texto francés.

Ante la imposibilidad de dejar constancia en este artículo de todas las modificaciones presentes en nuestra versión, señalaremos sólo algunas pocas que sirvan al menos para caracterizarla. Varios son los cambios que tienden, como no podía ser menos, a aproximar la obra a sus oyentes o lectores. Tales cambios los encontramos sobre todo, pero no solamente, en lo relativo a vestimenta y culinaria.

En relación con lo primero, las frases de Harpagon reconviniendo a su hijo por sus dispendios (act. I, esc. 4): “Yo quisiera saber ... de qué sirven todas esas cintas con que vais cubierto de pies a cabeza y si media docena de pasadores no bastan para sujetar unos calzones. ¿Es necesario gastar dinero en pelucas, cuando se pueden llevar los cabellos al natural, que no cuestan nada?", se convierten en la versión sefardí en (ibid.): "Yo quería bien saber a cuálo sierven estos botones de camiśa de oro y este diamante que tú tienes en la grabata? ¿No se pueden meter de estos botones que no costan que 
algunos soldos? ¿A cuálo sierve esta cadena de oro tan valutośa? ¿No se viene a meter una de fiero? ¿Para cuálo es trocar el chapeo cada tres o cuatro meśes? ¿No lo puedes tener unos cuantos años?»

En cuanto a las comidas, cuando Harpagon encarga a su cocinero prepararle un banquete (act. III, esc. 1), éste piensa en "quatre grands potages ... Entrées", "rôt», "entremets", mientras que su amo le recomienda "haricot» y "pâte en pot bien garni de marrons». En cambio el "guiśandón" sefardí propone (act. III, esc. 4) "cuatro grandes platos de sopa y tres platos de comida ... lugumbres", "costías asadas" y "pollos", a lo que Harpagon le replica que "unas buenas habas" y "un aroz bien apretado». Y por supuesto, el cerdo al que alude maese Jacques (act. $v$, esc. 2) se convierte ahora (act. IV, esc. 5) en un "pato".

Reflejo costumbrista parece aflorar también en la contestación que Harpagon le da a su cochero, cuando éste, ante el mal estado de los caballos, se niega a enjaezarlos para llevarlos a la feria (act. III, esc. 5): "Si tú no los queres llevar, ya los llevaré yo miśmo; demás que la moda de agora ya permite de llevar el patrón miśmo la caroza»; en tanto que en el texto francés y en boca de Valère leemos (act. III, esc. 1): «Monsieur, j’obligerai le voisin le Picard à se charger de les conduire..."

Si bien el texto sefardí presenta escasísimos turquismos, la influencia del medio ambiente turco se deja sentir cuando Harpagon al descubrir que ha desaparecido la arqueta donde esconde su dinero, exclama (act. IV, esc. 4): «Haide, presto, chaušes ['guardias'], kavaśes ['corchetes'], źaptiés ['gendarmes'], cuchíos, forcas, gelates ['verdugos']", valiéndose de las palabras turcas cavus, kavas, zaptiye y cellat para referirse a los brazos armados de la justicia. El paralelo texto francés dice (act. IV, esc. 7): "Allons, vite, des commissaires, des archers, des prévôts, des juges, des genes, des potences et des bourreaux".

A elementales tacto y prudencia se deben otros cambios, como la eliminación de boca de Anrico (act. II, esc. 1) de los apelativos de judío y árabe con que Cléante indignado apostrofa al prestamista que le exige unas condiciones leoninas (ibid.), y la desaparición de las no aconsejables alusiones a los turcos, como la del parlamento de La Flèche, quien al describir a Frosine (fr. act. II esc. $4 /$ jesp. esc. 5) la dureza de Harpagon, le dice: "Il est Turc là-dessus, mais d'une turquerie à désespérer tout le monde», o cuando la misma 
Frosine, al alabarse ante Harpagon de sus buenos oficios como casamentera, afirma (fr. act. II, esc. 5 / jesp. esc. 6): "Yo creo que si se me pusiera en la cabeza, casaría al Gran Turco con la República de Venecia".

Pero los cambios que presentan un mayor interés son los que afectan al contenido mismo de la obra: De ellos ya nos ilustran los nombres ausentes de la lista de personajes. La eliminación de Élise y Valère obliga al adaptador a manipular sus respectivos parlamentos a lo largo de toda la obra, los cuales no siempre desaparecen sino que son adjudicados, remodelándolos, a otros personajes; así Anrico (Cléante) asume mucho de lo dicho por Élise y Valère, quien también presta parte de sus palabras al propio Harpagon.

Por poner algún ejemplo, digamos que de entrada la versión judeoespañola empieza con una conversación entre Anrico e Iśabela, aprovechando los materiales de la conversación inicial del texto francés entre los dos desaparecidos Valère y Élise.

La remodelación textual se hace con cierto gracejo y habilidad, que alcanza su mayor logro literario en el reajuste de la escena 5 del primer acto del original. Allí tiene lugar la conversación entre Harpagon y Valère, a quien ha tomado el primero como mediador en su disputa con su hija ante la negativa de ésta de casarse con Anselmo (traduzco del original):

Harpagon.- ¿Cómo? El señor Anselmo es un partido notable, es un gentilhombre auténtico, tierno, sentado, sabio y muy rico, a quien no le queda ningún hijo de su primer matrimonio. ¿Podría encontrar ella algo mejor?

Valère.- Eso es cierto. Mas ella podría deciros que es precipitar las cosas un poco y que sería preciso al menos cierto tiempo para ver si su inclinación podría acomodarse con...

Harpagon.- Es una ocasión que hay que coger por los pelos. Yo obtengo en ello una ventaja que no encontraría en otro lado y es que se compromete a tomarla sin dote.

Valère.- ¿Sin dote?

Harpagon.- Sí.

Valère.- ¡Ah! Entonces me callo. ¿Veis?, esa es una razón completamente convincente; hay que rendirse ante ella.

Harpagon.- Para mí significa un ahorro considerable. 
Valère.- Seguro; eso no admite contradicción. Es verdad que vuestra hija podría alegar que el matrimonio es un asunto mucho más importante de lo que pueda creerse; que en ello va el ser feliz o desgraciado toda la vida y que un compromiso que debe durar hasta la muerte hay que hacerlo siempre con grandes precuaciones.

Harpagon.- ¡Sin dote!

Valère.- ¡Ah! Eso no admite réplica. ¿Quién diantres puede objetarlo? Eso no quiere decir que no haya muchos padres que prefieran atender a la satisfacción de sus hijas antes que al dinero que pudieran entregar; que no quisieran sacrificarlas al interés y que intentaran, por encima de todo, introducir en un matrimonio esa dulce conformidad que sin cesar mantiene en él el honor, la tranquilidad y la alegría y que...

Harpagon.- !Sin dote!

Valère.- Es cierto. Eso le cierra la boca a cualquiera. ¡Sin dote! ¡No hay modo de resistir a una razón semejante!

En la versión judeoespañola la discusión se establece entre Harpagon y Anrico por la esposa que el padre le ha dispuesto (act. I, esc. 8):

Arpagón.- ¿Cómo? Esta mujer que te vo a dar es un partido muy bueno. Una mujer noble, sabia, rica, que no tiene criaturas del otro caśamiento. Es verdad que es un poco de edad, ma no se mira la edad cuando te están dando cincuenta mil francos.

Anrico.- Esto ya es verdad, ma el caśamiento es una cośa sobre la cuala se debe pensar y no haćerla prestamente. $Y$ más, se quere algún tiempo para haćer la conocencia de esta mujer, y al fin...

Arpagón.- Ma esto es una ocaśión que se debe apañar prestamente por tomar cincuenta mil francos.

Anrico.- ¡A A ! Yo no digo más.

Arpagón.- Esto es para mí un buen capital.

Anrico.- Seguramente. Ma es menester pensar que un caśamiento es para toda la vida y que él puede haćer la persona venturośa o deśgraciada, por lo cual no se debe apresurar muncho.

Arpagón.- ¡Cincuenta mil francos!

Anrico.- Ya tenés raźón. Esto haće determinar todo. Ma es 
menester conocer la persona con la cuala se va caśar y no haćer todo con los ojos tapados.

Arpagón.- ¡Cincuenta mil francos!

Anrico.- ¡Ah! No se puede responder para esto. Algunos padres hay que bušcan antes de todo el repośo y la contentez y después la moneda.

Arpagón.- ¡Cincuenta mil francos!

Anrico.- Ya es verdad. Esto cera la boca. ¡Cincuenta mil francos! ¿Qué repuesta se da para esto? Y cuando se diće cincuenta mil francos se toma todo lo que vos dan.

En esencia, la escena es la misma y con los mismos argumentos; el cambio de personajes entre Valère, defensor de Élise, y el hijo Anrico que se defiende a sí mismo, se subsana con la diferencia entre la dote que no se da y la dote que se cobra.

El único error que he podido detectar en la versión judeoespañola en este baile de parlamentos y personajes aparece en el segundo acto, escena 2 de ambos textos. Aquí, cuando ham Šim 'ón, agente mediador entre el prestamista Harpagon y el prestatario Anrico sin conocer su relación familiar, descubre a este último y a su criado Alberto en casa del avaro, dice, señalando a Anrico: "Este Sr. es que quere tomarvos prestado los quince mil francos donde yo vos hablí", a lo que el avaro contesta, dirigiéndose sorprendentemente "a Alberto: ¿Cómo? ¿Sos tú, pero, que queres haćer estos gastes?»; y ahora nos encontramos con que el criado Alberto responde: «¿Cómo, mi padre? ¿Es vos que haćés estas verguenzośas hechas?»

Obviamente la conversación transcurre en el original entre padre e hijo y no entre el patrón y el criado de Cléante, y el apelativo que el asombrado Harpagon aplica a su hijo es el de pendard, es decir, 'vago, bigardo' y no el más fuerte perro de la versión judeoespañola.

Es imposible plasmar aquí los muchos otros cambios que contribuyen a remodelar profundamente la obra de Molière. Digamos simplemente que no tiene cabida en esta cuasi nueva obra la anagnórisis final en la que Anselme, prometido por su padre a Élise, reconoce en Valère y en Mariane a sus hijos perdidos (act. V, esc. 5), con lo cual el Se. Ferdinando, remedo muy deslucido de Anselme, a quien desde la lista de personajes se ha presentado como padre de Iśabela (es decir, de Mariane), aparece al final (act. IV, esc. 7) solamente para rogar a Harpagon que consienta en la boda de su 
hija con Anrico. No deja de ser curioso, sin embargo, que después de tantos cambios el traductor sefardí se haya preocupado de acabar su versión con las mismas palabras que en el original. Cuando el Se. Ferdinando exhorta a todos a regocijarse con la boda, Harpagon contesta (act. IV, esc. 7): "Y yo ver mi querida cajita", en tanto que en el texto francés leemos (act. $V$, esc. 6): «Et moi, voir ma chère cassette».

Digamos para terminar que la obra de Molière gozó de un especial favor por parte del público sefardí, sobre todo del de Salónica, donde podemos documentar representaciones en 1910, 1914-1915, 1920 y 1928, y también una en Serre en $1916^{12}$. Conocemos además de ésta otras dos ediciones, ambas de Salónica: la primera apareció en 1884, adaptada por David J. Hassid, y la segunda hacia 1904 en adaptación de Joseph Nehama, la cual no ha llegado a mis manos ${ }^{13}$.

Comparando la presente versión con la de Hassid, puedo afirmar ahora que no existe ninguna relación entre ambas, siendo sin duda dos adaptaciones diferentes del originial y bastante más amplia la última.

No dejan, sin embargo, de ser chocantes algunas coincidencias, de las que sólo mencionaremos que también en la traducción de Hassid aparecen cambiados los nombres de los personajes, usándose para los principales una serie de nombres neutros que evitan el exotismo de los molierescos. Entre ellos encontramos el de Anrico, que ahora corresponde al Valère del original, y el de Alberto que en este caso corresponde a Cléante, o lo que es lo mismo, al Anrico de la versión que hemos estudiado.

Sólo me resta ofrecer este artículo a mi muy admirado y querido amigo, David Romano *.

12 Vid. Repertorio, nos 354, 493, 522, 556, 619-626 y 739.

13 Vid. Teatro: “Repertorio dramático", vol. I, págs. 165-175.

- Al cual muy bien puede aplicarse el dicho de que detrás de un gran hombre siempre hay una gran mujer. 


\section{RESUMEN}

En el presente artículo se estudian tres obras de teatro en judeoespañol que son sendas versiones de El avaro y El matrimonio forzado de Molière y de Esther de Racine; además del examen de varios aspectos de estas obras, también se lleva a cabo un análisis comparativo de los textos con sus respectivos originales.

\section{SUMMARY}

The present article deals with three plays in Judaeo-Spanish language which are the corresponding versions of Molière's L'Avare and Le Mariage forcé, and Racine's Esther. Apart from examining several aspects of these works, a comparative analysis of the texts with the originals is also being made. 